\title{
Capillary electrophoretic and extraction conditions for the analysis of Catha edulis FORKS active principles
}

\author{
Gabriella Roda ${ }^{\mathrm{a}, *}$, Vincenzo Liberti ${ }^{\mathrm{a}}$, Sebastiano Arnoldi ${ }^{\mathrm{a}}$, Antonella Argo ${ }^{\mathrm{b}}$, Chiara Rusconi $^{\mathrm{a}}$, \\ Sonia Suardi ${ }^{a}$, Veniero Gambaro ${ }^{a}$ \\ a Dipartimento di Scienze Farmaceutiche, Università degli Studi di Milano, Via Mangiagalli 25, 20133 Milano, Italy \\ ${ }^{\mathrm{b}}$ Istituto di Medicina Legale e delle Assicurazioni Policlinico Universitario, Via del Vespro n. 129, 90127 Palermo, Italy
}

\section{A R T I C L E I N F O}

\section{Article history:}

Received 8 January 2013

Received in revised form 12 February 2013

Accepted 22 February 2013

Available online

\section{Keywords:}

Catha edulis

Cathinone

Cathine

Phenylpropanolamine

CE

\begin{abstract}
A B S T R A C T
A capillary electrophoretic method, which allowed the detection and separation of the active principles of Catha edulis, i.e. cathinone, cathine and phenylpropanolamine, was developed. A suitable internal standard (nicotinamide), which permitted the quantification of the analytes reducing the variability of the migration times due to EOF changes, was identified. The analytical method was validated, assessing linearity, sensitivity and repeatability, showing optimal features for the analysis of the vegetable material. Moreover extraction conditions were investigated to achieve the exhaustion of the plant material in the fastest and most efficient way to meet the requirements of the Court.
\end{abstract}

(c) 2013 Elsevier Ireland Ltd. All rights reserved.

\section{Introduction}

Catha edulis (khat), a flowering evergreen shrub or small tree belonging to the Celastraceae family, characterized by oval opposite finely toothed leaves, is native and mainly cultivated in East Africa and Arabian Peninsula [1-3]. The chewing of fresh leaves or the smoking of dried plant material is a common social and traditional habit in these countries [4]. The effect of khat assumption is mild excitation and euphoria, that is a psychoactive stimulation similar to that produced by amphetamines [5]. Khat contains three alkaloids with an amphetamine-like structure (Fig. 1): cathinone $[(S)-(-)-\alpha$-aminopropiophenone, 1], cathine $[(S, S)-(+)$-norpseudoephedrine, 2] and phenylpropanolamine $[(R, S)-(-)$-norephedrine, PPA, 3] [6,7], but the psychostimulation is predominately, or even exclusively due to cathinone, whose effect is believed to be mediated by the dopaminergic system.

Cathine is less active as a stimulant, and PPA has no psychotropic effect [8]. After harvesting, cathinone is enzimatically converted into cathine and norephedrine [6] and due to the limited shelf life of the most active component in the fresh vegetable material, the storage of the plant is crucial for the identification and quantification of this psychoactive component, which is,

\footnotetext{
* Corresponding author. Tel.: +39 02 50319328; fax: +39 0250319359 .

E-mail address: gabriella.roda@unimi.it (G. Roda).
}

together with cathine, regulated as a controlled substance in many countries. In fact it was demonstrated that cathinone is stable for years in the dried khat, but it undergoes rapid decomposition in the fresh or frozen vegetable material [9]. Several analytical methods were developed for the determination of khat alkaloids either involving GC and HPLC techniques [10-14]; in the last years, the Tribunal of Busto Arsizio and Bergamo gave us the task to analyze all the materials suspected to contain khat active principles, coming from the seizures at the Malpensa and Orio al Serio airports in northern Italy. Thus, due to the high number of samples to be analyzed, we developed a fast, effective and reliable GC analytical procedure able to simultaneously detect, cathine and PPA, whose discrimination was mandatory because PPA is not a controlled psychoactive agent, exploiting a derivatization protocol which allowed an effective separation of the two components without dramatically increasing the time of analyses [15].

In this frame we were interested in the application of capillary electrophoresis, a technique, complementary to GC, endowed with similar characteristics of rapidity, selectivity and sensitivity, which is gaining importance in the forensic analysis [16] and which was applied to the separation of several amphetamine derivatives in the presence of chiral additives [17]. In this work, being not interested in chiral separations because the active principles contained in the vegetable material are enatiomerically pure, we tried to simplify the analytical method and to optimize the 
<smiles>CC(N)C(=O)c1ccccc1</smiles>

cathinone<smiles>C[C@@H](N)C(O)c1ccccc1</smiles>

cathine<smiles>CC(N)[C@H](O)c1ccccc1</smiles>

PPA<smiles>NC(=O)c1cccnc1</smiles>

nicotinamide

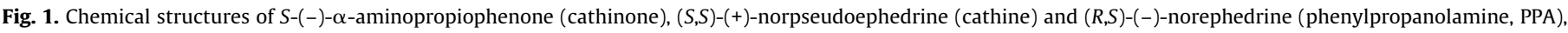
pyridine-3-carboxamide (nicotinamide).

extraction procedure to meet the requirements of the Court. Several parameters of the extraction protocol were considered in order to find the most suitable conditions for the treatment of this perishable vegetable material; moreover the electrophoretic method was validated following the guidance on validation published by the European Medicines Agency [18].

\section{Experimental}

\subsection{Reagents}

Phosphoric acid, sodium hydroxide, trizma base, acetone, methanol, phenylpropanolamine hydrochloride, nicotinamide and ethyl acetate were obtained from Sigma-Aldrich. All reagents used were of analytical grade and all reagents, standard solutions and buffers were prepared with water obtained from a Milli-Q water purification system (Millipore).

\subsection{Standards}

Cathinone was purchased from LGC PROMOCHEM s.r.l., while a $1 \mathrm{mg} / \mathrm{mL}$ solution of cathine in methanol from S.A.L.A.R.S. s.p.a.

Stock solutions of $100 \mu \mathrm{g} / \mathrm{mL}$ of cathinone, cathine and phenylpropanolamine were prepared in methanol.

\subsection{Vegetable material}

The vegetable material studied (bundle 1) was seized in January 2011 and was delivered to our laboratory by the Tribunal of Busto Arsizio. It was composed by 120 bunches contained in a traveling bag. The vegetable material was completely frozen after the seizure and it was kept refrigerated until the analyses. 10 representative bundles were withdrawn from the seized material to be analyzed. Every bundle was composed of a variable number of $C$. edulis twigs divided into small groups and tied with strands of raffia. The leaves and stems of the vegetable material were wrapped with blotting paper and covered with a banana leaf.

The vegetable material from which bundle 2 was taken was seized in February 2012 and was composed of 38 bunches of $C$. edulis, the vegetable material from which bundle 3 was taken was composed of 15 bunches, seized in July 2012 in northern Italy and were delivered to our laboratory by the Tribunal of Busto Arsizio.

The plant material underwent a preliminary botanical examination in order to establish the species. From a legal point of view, therefore it was necessary to unequivocally determine and quantify the active principles.

\subsection{Method development}

Several parameters were taken into account in the development of the extraction protocol: solvent, method of extraction and time of contact. All the proofs were carried out starting from $1 \mathrm{~g}$ of dry vegetable material, which was suspended in $10 \mathrm{~mL}$ of extracting solvent.

\subsubsection{Preparation of the vegetable material}

Frozen leaves and stems were manually separated and dried at room temperature on blotting paper for $48 \mathrm{~h}$. The dry vegetable material was stored up in plastic bags until use.

\subsubsection{Solvent of extraction}

Three different solvents were evaluated: methanol, ethyl acetate and chloroform. Leaves and stems were chopped and mixed in order to obtain a homogeneous vegetable material $(1 \mathrm{~g})$, which was added with the extraction solvent $(10 \mathrm{~mL})$. The mixture was vigorously stirred for $1 \mathrm{~min}$ and then macerated at room temperature. The solvent $(100 \mu \mathrm{L})$ was withdrawn every $24 \mathrm{~h}$ to control the progress of the extraction. In the case of ethyl acetate and chloroform the solvent was evaporated and the residue recovered with water.

\subsubsection{Method of extraction}

Three different extraction methods were compared:

Maceration: $1 \mathrm{~g}$ of leaves and stems manually chopped in pieces of about $0.5 \mathrm{~cm}$ were suspended in $10 \mathrm{~mL}$ of solvent in a round flask, vigorously mixed for $1 \mathrm{~min}$ and macerated for $24 \mathrm{~h}$. Every hour the solvent $(100 \mu \mathrm{L})$ was withdrawn to control the progress of the extraction.

Extraction with a rotary extractor: the vegetable material suspended in the organic solvent was put on a rotary extractor and rotated for $7 \mathrm{~h}$. Every hour the solvent $(100 \mu \mathrm{L})$ was withdrawn to control the progress of the extraction.

Ultrasound extraction: three samples ( $1 \mathrm{~g}$ of leaves and $1 \mathrm{~g}$ of stems) were suspended in $10 \mathrm{~mL}$ of solvent. The first sample was sonicated for $20 \mathrm{~min}$ and then allowed to stand at room temperature for $40 \mathrm{~min}$, The second was sonicated for $40 \mathrm{~min}$ and allowed to stand for $20 \mathrm{~min}$. The third was sonicated for $60 \mathrm{~min}$. After $60 \mathrm{~min}$ the solvent $(100 \mu \mathrm{L})$ was withdrawn to control the progress of the extraction.

\subsubsection{Time of contact}

The progress of the extraction ( $1 \mathrm{~g}$ of leaves and $1 \mathrm{~g}$ of stems suspended in $10 \mathrm{~mL}$ of solvent) was monitored during the first $7 \mathrm{~h}$ withdrawing $100 \mu \mathrm{L}$ of solvent, then the solvent was analyzed after $24 \mathrm{~h}$ and once a day for 5 days, either changing the solvent every day or without changing the solvent, in order to evaluate the time necessary to exhaust the vegetable drug. To shorten the time of extraction other two proofs were carried out (with or without changing the solvent) with $100 \mathrm{mg}$ of vegetable material.

\subsubsection{Evaluation of the distribution of the active principles}

The vegetable material was separated into leaves, tender stems and woody stems. $1 \mathrm{~g}$ of the different parts of the plant were exactly weighted and suspended in $10 \mathrm{~mL}$ of solvent.

\subsubsection{Drying of the vegetable material}

The stability of the active principles was evaluated: 3 samples of frozen leaves $(1 \mathrm{~g})$ and 3 samples of frozen stems $(1 \mathrm{~g})$ were directly extracted; 3 samples of frozen leaves ( $1 \mathrm{~g}$ ) and 3 samples of frozen stems $(1 \mathrm{~g})$ were dried at $35^{\circ} \mathrm{C}$ and then extracted. In order to simplify the preparation of the vegetable material a whole 
bundle of $C$. edulis was dried at $35{ }^{\circ} \mathrm{C}$. The dried vegetable material was homogenized an extracted.

\subsubsection{Optimal extraction conditions}

$100 \mathrm{mg}$ of mixed vegetable material coming from a whole bundle $(77.520 \mathrm{~g})$ were macerated in methanol at room temperature $(10 \mathrm{~mL})$ for $48 \mathrm{~h}$, changing the solvent after $24 \mathrm{~h}$. Then from the combined extracts $100 \mu \mathrm{L}$ were withdrawn and analyzed in CE (see Section 2.5).

\subsection{Apparatus}

Capillary electrophoretic (CE) experiments were carried out using a Beckman Coulter ProteomeLab PA 800 system equipped with a diode-array detector scanning from 190 to $600 \mathrm{~nm}$. A 32 Karat software was employed for instrument control, data acquisition and data analysis. Electrophoretic separations were performed under the conventional operating conditions (anodic injection) in an uncoated fused-silica capillary of $62 \mathrm{~cm}$ total length, $50 \mathrm{~cm}$ effective length and $50 \mu \mathrm{m}$ i.d. (Composite Metal Service Ltd.). New capillaries were preliminarily conditioned as follows: 30 min with $0.1 \mathrm{M} \mathrm{NaOH}, 30 \mathrm{~min}$ with water and $30 \mathrm{~min}$ with the running buffer. Between runs, the capillary was activated with $0.1 \mathrm{M} \mathrm{NaOH}$ for $3 \mathrm{~min}$, rinsed with water for $3 \mathrm{~min}$ and with background electrolyte (BGE) for $5 \mathrm{~min}$. Activation, rinse and equilibrations steps were all carried out with a pressure of $40 \mathrm{psi}$. All injections were performed in the hydrodynamic mode $(20 \mathrm{~s}$, $1.0 \mathrm{psi}$ ). The capillary was operated at $30 \mathrm{kV}$, while maintaining its temperature at $25^{\circ} \mathrm{C}$; detection was carried out with a DAD detector scanning from 190 to $400 \mathrm{~nm}$. Quantitative determinations were carried out at $210 \mathrm{~nm}$, since at this wavelength the samples showed their higher peak absorbance. The $\mathrm{pH}$ values of the running buffers were measured with a MP $220 \mathrm{pH}$ meter (Mettler Toledo) equipped with an electrode InLab 418 (Mettler Toledo), daily calibrated.

$25 \mathrm{mM}$ TRIS phosphate buffer ( $\mathrm{pH}$ 2.5) was prepared dissolving $605.7 \mathrm{mg}$ of Trizma base in $200 \mathrm{~mL}$ of water and the $\mathrm{pH}$ was adjusted with a saturated solution of phosphoric acid $99 \%$.

\subsection{Sample preparation}

When preparing the samples for the electrophoretic analysis it is mandatory that the percentage of organic solvent do not exceed $20 \%(\mathrm{v} / \mathrm{v}$ ) of the aqueous medium. Moreover an internal standard is needed to minimize the EOF variations leading to consistent differences in the absolute electrophoretic migrations.

The samples were prepared as follows: $100 \mu \mathrm{L}$ of extract or standard solution $(0.1 \mathrm{mg} / \mathrm{mL}), 100 \mu \mathrm{L}$ of nicotinamide (IS, $0.1 \mathrm{mg} /$ $\mathrm{mL})$ and $1.8 \mathrm{~mL}$ of water.

\subsection{Linearity}

Linearity of detector response was evaluated for each analyte preparing five standard solution at a concentration of $10,20,50$, 100 and $200 \mu \mathrm{g} / \mathrm{mL}$ adding nicotinamide $(0.1 \mathrm{mg} / \mathrm{mL})$.

\subsection{Sensitivity}

LOD and LOQ were evaluated progressively diluting standards solutions $(0.1 \mathrm{mg} / \mathrm{mL})$ of the active principles. LOD was determined as the lowest detectable analyte concentration which was at least 3 times higher than the standard deviation of the signal to noise ratio. LOQ was determined as the lowest analyte concentration which could be quantified and was at least 10 times higher than the standard deviation of the signal to noise ratio.

\subsection{Repeatabilty}

Intra-day repeatability was assessed analysing the same extract six times in the same day; inter day repeatability was obtained analysing the same sample every $24 \mathrm{~h}$ for four consecutive days.

As regard as intra-day repeatability, relative retention times respect to the internal standard value resulted $1.038 \pm 0.026$ for cathinone, $1.081 \pm 0.030$ for cathine and $1.091 \pm 0.030$ for PPA, whereas relative peak areas respect to the internal standard value were $6.352 \pm 0.151$ for cathinone, $2.427 \pm 0.127$ for cathine and $0.609 \pm 0.093$ for PPA. As regard as inter-day repeatability, relative retention times respect to the internal standard value resulted $1.044 \pm 0.023$ for cathinone, $1.063 \pm 0.020$ for cathine and $1.108 \pm 0.032$ for PPA, whereas relative peak areas respect to the internal standard value were $6.238 \pm 0.143$ for cathinone, $2.325 \pm 0.118$ for cathine and $0.626 \pm 0.090$ for PPA.

\subsection{Accuracy}

Accuracy was assessed calculating the \% recovery of the analytes defined as \% Rec analyte $=\left(C_{\exp } / C_{\text {theo }}\right) \times 100$ where $C_{\exp }$ is the experimental concentration of the analyte and $C_{\text {theo }}$ is its theoretical concentration. Accuracy was evaluated in triplicate spiking previously exhausted khat plant material at the concentration of 0.1 and $0.01 \mathrm{mg} / \mathrm{mL}$ of all the analytes. Accuracy ranged from $96.9 \%$ to $106.7 \%$ at $0.01 \mathrm{mg} / \mathrm{mL}$ and from $94.8 \%$ to $102.7 \%$ at $0.1 \mathrm{mg} / \mathrm{mL}$ for cathinone, from $98.2 \%$ to $103.2 \%$ at $0.01 \mathrm{mg} / \mathrm{mL}$ and from $96.6 \%$ to $107.0 \%$ at $0.1 \mathrm{mg} / \mathrm{mL}$ for cathine and from $98.5 \%$ to $103.3 \%$ at $0.01 \mathrm{mg} / \mathrm{mL}$ and from $97.8 \%$ to $103.1 \%$ at $0.1 \mathrm{mg} / \mathrm{mL}$ for PPA.

\section{Results and discussion}

For the optimization of the electrophoretic method a mixture of the standards of the active principles, i.e. cathinone, cathine and PPA, was used. Several buffers at different $\mathrm{pH}$ and concentrations were tested. Moreover the best operating temperature and voltage were assessed, to obtain a good resolution in a short time of analysis.

The buffer which provided the optimal separation of the peaks (6 min of analysis) was $25 \mathrm{mM}$ TRIS Phosphate buffer $\mathrm{pH} 2.5$, operated at $30 \mathrm{kV}$, maintaining the temperature of the capillary at $25{ }^{\circ} \mathrm{C}$ (Fig. 2). Afterwards an extract of the whole vegetable material was analyzed in the condition described to verify that there were no interference with the analytes of interest. In the electrophoretic conditions, basic substances migrates faster than neutral or acidic compounds, so it was possible to separate the three main basic active principles contained in khat from the other components of the vegetable matrix in a short time. This means that this technique is much more selective than other methods such as GC or HPLC in which more complex chromatograms are obtained [15], moreover no derivatization procedures are required. In order to quantify the active principles and to minimize the EOF variations, an internal standard (IS) was sought, whose time of migration and electrophoretic characteristics were compatible with those of the analytes of interest. Various amphetamine derivatives were investigated, but neither of them showed optimal features, interfering with the khat alkaloids. Nicotinamide was identified as suitable IS, having a migration time of about $30 \mathrm{~s}$ shorter than those of cathinone, the first eluting peak (Fig. 2). The IS retention time was used to calculate relative migration times of the analytes in order to increase reproducibility and the ratio between the area of the analytes and the IS area was reported to account for injection volume and dilution volume variations.

The electrophoretic method was validated in accordance with the guidelines provided by the European Medicines Agency [18]. 


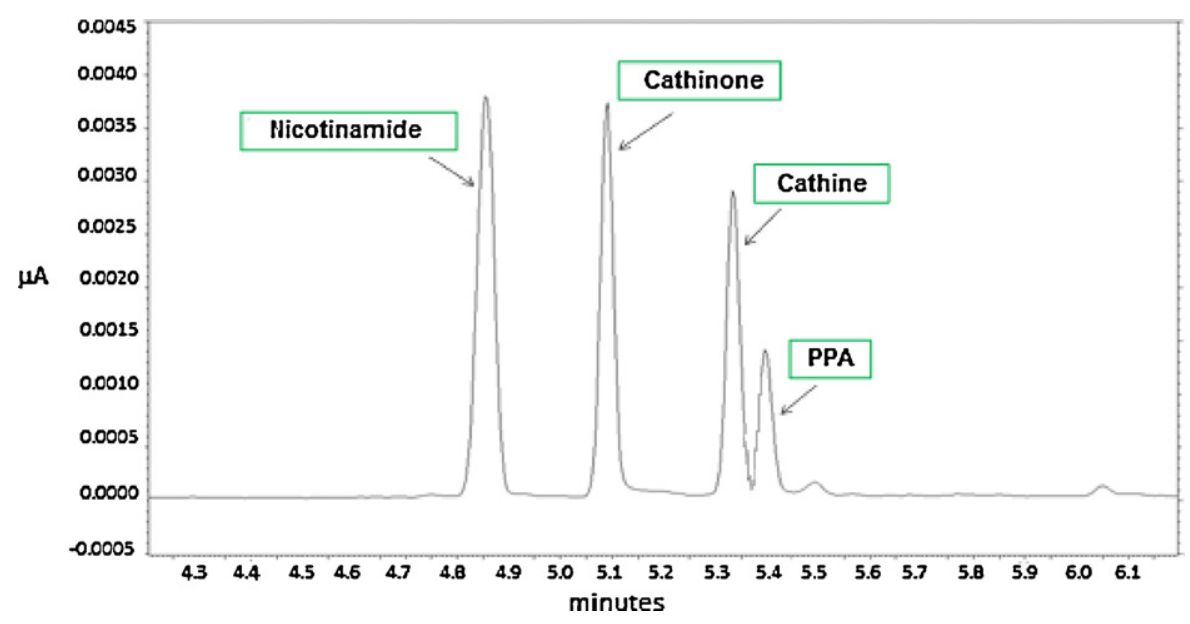

Fig. 2. Electropherogram of an extract containing the active principles of Catha edulis in the presence of IS (migration times: $4.292,4.458,4.638,4.683$ ).

The linearity of the DAD detector was checked for cathinone, cathine, and PPA preparing standard solution containing the IS as described in Section 2.7. The linearity of the calibration functions was satisfactory over the whole range. The calibration functions were $y=0.0038 x-0.0281 \quad\left(R^{2}=0.9938\right)$ for cathinone, $y=0.0028 x-0.0186\left(R^{2}=0.9938\right)$ for cathine and $y=0.0012 x-$ $0.0106\left(R^{2}=0.9988\right)$ for PPA, being $y$ the ratio between the analyte area and the internal standard area and $x$ the concentration of the standard solution $(\mu \mathrm{g} / \mathrm{mL})$.

Sensitivity was assessed diluting the standard solutions until LOQ $(0.4 \mu \mathrm{g} / \mathrm{mL})$ and LOD $(0.2 \mu \mathrm{g} / \mathrm{mL})$ were reached.

Intra-day repeatability was evaluated analysing the same extract six times in the same day; inter-day repeatability was obtained analysing the same sample once a day for four consecutive days (see Section 2.9). The \%RSD values both related to the peak areas and to the migration time indicated that the method showed a suitable repeatability in the interval of time requested by the Court for the analyses. Even accuracy, obtained spiking a previously exhausted vegetable material with a known amount of the analytes, showed adequate values (see Section 2.10).

Once established the suitability of the analytical method for the determination of the alkaloids of $C$. edulis, attention was devoted to the optimization of the extraction conditions. The first issue taken into account was the extraction solvent: first of all an acidic aqueous solution was tested but the electropherogram resulted contaminated by several interfering species, then three different organic extraction media were evaluated: methanol, ethyl acetate and chloroform. From the electropherograms of the extractions carried out with these three solvents it was evident that only methanol was able to extract in an efficient way the active principles. In a previous paper [15] we reported as optimal conditions for the extraction of the analytes a liquid-liquid extraction with ethyl acetate. In this case we decided to macerate the vegetable material with pure organic solvents in order to simplify the extraction protocol and to avoid the phase separation step and the evaporation of the solvent. Methanol is particularly convenient because the extract can be diluted with the running buffer and directly injected in the instrument (see Section 2.6).

As regards as the extraction method, ultrasounds were not suitable, leading to the heating of the extraction solvent and to the decomposition of the active principles. The use of the rotary extractor did not result in improvement neither in the extraction yield nor in the extraction time. Simple maceration was therefore considered the method of choice for the extraction of khat alkaloids.

From the above mentioned proofs it was evident that it was not possible to exhaust the vegetable material $(1 \mathrm{~g}$ in $10 \mathrm{~mL}$ methanol) in $24 \mathrm{~h}$. Thus the progress of the extraction was monitored day by day either changing the solvent every $24 \mathrm{~h}$ or without changing the solvent, in order to evaluate the most effective, cheapest and fastest protocol. Leaves and stems were suspended in methanol and a little amount of the extraction solvent was withdrawn every day for 4 days. Without changing the solvent, saturation was reached in $24 \mathrm{~h}$ and it was not possible to exhaust the drug even prolonging the time of extraction. On the other hand, changing the solvent every day the vegatable material was completely exhausted in 4 days. In these conditions all the analytes resulted stable for all the time of the extraction-analysis protocol.

From the analyses of the active principles in the various parts of the vegetable material it could be noticed that in the leaves all the three alkaloids were detected, whereas in the stems only cathinone and cathine were present, being PPA detectable only in traces. This finding confirmed what was reported in the literature $[11,15]$. In the woody stems only low amounts of cathinone were found confirming the hypothesis that the most active alkaloid is enzymatically converted into cathine and PPA in the older parts of the plant (Table 1 ).

The drying of the vegetable material was then taken into account to confirm what was found in the study on the determination of the alkaloids of $C$. edulis by GC [15]. Three samples of frozen leaves and stems were dried in a heater at $35{ }^{\circ} \mathrm{C}$ and weighted every hour to determine the loss on drying, which

Table 1

Peak areas and relative percentages of the active principles in the various parts of the plant.

\begin{tabular}{|c|c|c|c|c|c|c|}
\hline Part of the plant & Cathinone area/IS area & Cathine area/IS area & PPA area/IS area & \% Cathinone & $\%$ Cathine & $\% \mathrm{PPA}$ \\
\hline Leaves & 3.266 & 0.977 & 0.609 & 48.0 & 21.6 & 30.4 \\
\hline Whole stems & 3.085 & 1.450 & 0 & 59.9 & 40.1 & 0 \\
\hline Woody stems & 0.212 & 0.554 & 0 & 32.6 & 67.4 & 0 \\
\hline Tender stems & 3.100 & 1.300 & 0 & 59.5 & 40.5 & 0 \\
\hline
\end{tabular}


Table 2

Comparison between frozen and dried vegetable material. The content of khat alkaloids in the frozen material was calculated on the dry weight.

\begin{tabular}{|c|c|c|c|}
\hline Leaves + Stems & Cathinone area/IS area & Cathine area/IS area & PPA area/IS area \\
\hline Dried vegetable material & 2.324 & 0.772 & 0.271 \\
\hline Frozen vegetable material & 2.271 & 0.812 & 0.255 \\
\hline Mean & 2.298 & 0.792 & 0.264 \\
\hline Standard deviation & 0.037 & 0.028 & 0.011 \\
\hline \% RSD & 1.61 & 3.59 & 4.32 \\
\hline
\end{tabular}

Table 3

Amount of active principles in bundles of Catha edulis coming from different seizures calculated on dry weight.

\begin{tabular}{|c|c|c|c|c|}
\hline & & Cathinone & Cathine & PPA \\
\hline \multirow[t]{4}{*}{ Bundle 1 (dry weight: $24.638 \mathrm{~g}$ ) } & Active principle area/IS area & 0.773 & 0.229 & 0.0734 \\
\hline & Concentration $(\mu \mathrm{g} / \mathrm{mL})$ & 27.7 & 15.0 & 9.4 \\
\hline & Total quantity in a bundle (mg) & 6.82 & 3.70 & 2.32 \\
\hline & Quantity in a bundle $(\mathrm{mg} / \mathrm{g})$ & 0.277 & 0.150 & 0.094 \\
\hline \multirow[t]{4}{*}{ Bundle 2 (dry weight: $26.380 \mathrm{~g}$ ) } & Active principle area/IS area & 3.176 & 1.120 & 0.251 \\
\hline & Concentration $(\mu \mathrm{g} / \mathrm{mL})$ & 90.9 & 47.3 & 29.5 \\
\hline & Total quantity in a bundle (mg) & 23.98 & 12.47 & 7.78 \\
\hline & Quantity in a bundle $(\mathrm{mg} / \mathrm{g})$ & 0.909 & 0.473 & 0.295 \\
\hline \multirow[t]{4}{*}{ Bundle 3 (dry weight: $20.810 \mathrm{~g}$ ) } & Active principle area/IS area & 3.831 & 6.279 & 1.153 \\
\hline & Concentration $(\mu \mathrm{g} / \mathrm{mL})$ & 108.2 & 234.2 & 104.1 \\
\hline & Total quantity in a bundle (mg) & 22.47 & 48.69 & 21.64 \\
\hline & Quantity in a bundle $(\mathrm{mg} / \mathrm{g})$ & 1.08 & 2.34 & 1.04 \\
\hline
\end{tabular}

varied from 67.5 to $68.5 \%$ for the leaves and from 72.2 to $74.3 \%$ for the stems.

As a result, a sample of dried leaves and stems was extracted following the optimized extraction protocol and compared with the extraction of a sample of frozen vegetable material. Comparing the areas of the active principles it was possible to conclude that drying did not alter their composition (Table 2), confirming what previously noticed [15] and literature data [9]. These findings were further confirmed by other studies carried out on khat samples analyzed by GC-FID technique [19].

Finally to speed up as much as possible the preparation of the vegetable material and the extraction procedure in order to meet the requirements of the Court, as the active principles are present in all the parts of the plant, even if in different amounts, a whole bundle of $C$. edulis was dried and homogenized. The active principles were quantified obtaining the results reported in Table 3. In this table three bundles coming from different seizures were taken into account. The concentration of the analyte was calculated from the ratio between the area of the analyte and the area of the IS taking into account the calibration curve. The analyte concentration was transformed in the total amount of the analyte considering that $1 \mathrm{~g}$ of the vegetable material was macerated in $10 \mathrm{~mL}$ of solvent.

In bundle 1 the quantity of the active principles were very low, perhaps due to a bad conservation of the vegetable material before coming to our laboratory. In fact generally dried khat contains from 0.9 to $4.5 \mathrm{mg} / \mathrm{g}$ of cathinone [1,9-11]. In bundles 2 and 3 the content of the active principles was superior and followed in the range reported in the literature. These bundles were also analyzed by means of GC/FID technique, confirming the quantity found by CE [19].

\section{Conclusions}

This work takes its origin from the necessity to develop an analytical method for the determination of the alkaloids contained in the $C$. edulis vegetable material seized by the police. This point is crucial because cathine and cathinone are included in the list of the illegal substances. The characterization of the active principles must be carried out either from a qualitative or from a quantitative point of view, in fact the quantitation of cathinone and cathine is very important to discriminate from personal use and drug dealing. To this end the seized vegetable material suspected to belong to $C$. edulis species undergoes a preliminary botanic examination and then for forensic purposes the active principles must be detected and quantified. In this frame a capillary electrophoretic method was developed, allowing the detection and separation of the active principles in 6 minutes of analysis. A suitable internal standard, i.e. nicotinamide, was identified, which permitted the quantification of the analytes reducing the variability of the migration times due to EOF changes. The analytical method was validated, assessing linearity, sensitivity, repeatability, and accuracy, showing optimal features for the analysis of the vegetable material. Moreover the conservation of the vegetable material was evaluated, confirming that drying is the best way to preserve the active principles $[9,15]$; the extraction conditions were investigated to achieve the exhaustion of the plant material in the fastest and most efficient way to meet the requirements of the Court.

Since extracting $1 \mathrm{~g}$ of vegetable material, the areas of the active principles were much higher than the LOQ to avoid solvent saturation only $100 \mathrm{mg}$ of homogenized vegetable material were withdrawn and extracted in $10 \mathrm{~mL}$ methanol. In this way the drug was exhausted in 2 days, changing the solvent after $24 \mathrm{~h}$.

\section{References}

[1] H.X. Schorno, Khat, suchtdroge des islams, Pharm. Unserer Zeit 11 (1982) 65-73.

[2] R. Brenneisen, S. Geisshüsler, Psychotropic drugs, Pharm. Acta Helv. 60 (1985) 290-301.

[3] S. Geisshüsler, R. Brenneisen, The content of psychoactive phenylpropyl and phenylpentenyl khatamines in Catha edulis Forks of different origin, J. Ethnopharmacol. 19 (1987) 269-277.

[4] M. Al-Quadhi, The Aftermath, Yemen Times (IX), Sana'a, 7 March 1999.

[5] P. Kalix, Khat, an amphetamine-like stimulant, J. Psychoactive Drugs 26 (1994) 69-74.

[6] R. Brenneisen, S. Geisshüsler, H.X. Schorno, Metabolism of cathinone to (-)norephedrine and (-)-norpseudoephedrine, J. Pharm. Pharmacol. 38 (1986) 298-300.

[7] K. Szendrei, The chemistry of khat, Bull. Narc. 32 (1980) 5-35

[8] M.A. Feyissa, J.P. Kelly, A review of the neuropharmacological properties of khat, Prog. Neuropsychopharmacol. Biol. Psychiatry 32 (2008) 1147-1166.

[9] J.S. Chappell, M.M. Lee, Cathinone preservation in khat evidence via drying, Forensic Sci. Int. 195 (2010) 108-120. 
[10] K. Mathys, R. Brenneisen, HPLC and TLC profiles of phenylalkylamines of khat (Catha edulis Forks) confiscated in Switzerland, Pharm. Acta Helv. 68 (1993) 121-128.

[11] T. Laussmann, S. Meier-Giebing, Forensic analysis of hallucinogenic mushrooms and khat (Catha edulis FORKS) using cation-exchange liquid chromatography, Forensic Sci. Int. 195 (2010) 160-164.

[12] L. Riapani, S. Schiavone, L. Garofano, GC/MS identification of Catha edulis stimulant-active principles, Forensic Sci. Int. 78 (1996) 39-46.

[13] J. Segura, R. Ventura, C. Jurado, Derivatization procedures for gas chromatographic-mass spectrometric determination of xenobiotics in biological samples, with special attention to drugs of abuse and doping agents, J. Chromatogr. B 713 (1998) 61-90.

[14] A.N. Guantai, C.K. Maitai, Relative distribution of cathinone and D-norpseudoephedrine in Catha edulis (miraa) growing in Kenya, East Afr. Med. J. 59 (1982) 394-398.
[15] V. Gambaro, S. Arnoldi, M.L. Colombo, L. Dell'Acqua, K. Guerrini, G. Roda, Determination of the active principles of Catha edulis: quali-quantitative analysis of cathinone, cathine, and phenylpropanolamine, Forensic Sci Int. 217 (2012) 87-92.

[16] F. Tagliaro, J. Pascali, E. Marchi, A. Fanigliulo, F. Bortolotti, Recent advances in the application of CE to forensic sciences: a update over years 2007-2009, Electrophoresis 31 (2010) 251-259.

[17] I.S. Lurle, R.F.X. Klein, T.A. Dal Cason, M.J. LeBelle, R. Brenneisen, R.E. Weinberger, Chiral resolution of cationic drugs of forensic interest by capillary electrophoresis with mixtures of neutral and anionic cyclodextrins, Anal. Chem. 66 (1994) 40194026.

[18] F.T. Peters, O.H. Drummer, F. Musshof, Validation of new methods, Forensic Sci. Int. 165 (2007) 216-224.

[19] L. Dell'Acqua, G. Roda, S. Arnoldi, C. Rusconi, L. Turati, V. Gambaro, Improved GC method for the determination of the active principles of Catha Edulis, J. Chromatogr. B., submitted for publication. 